\title{
Interfacial Phenomena between Lithium Ion Conductors and Cathodes
}

Hirotoshi Yamada*, Kentaro Suzuki, Kento Nishio, Koshin Takemoto, Gakuho Isomichi, Isamu Moriguchi

Graduate School of Engineering, Nagasaki University,

1-14, Bunkyo-machi, Nagasaki 8528521, Japan

*Corresponding author:

1-14, Bunkyo-machi, Nagasaki 8528521, Japan

e-mail: h-yama@nagasaki-u.ac.jp

TEL/FAX: +81-95-819-2861 


\begin{abstract}
Nanocomposites of a lithium ion conductor $\mathrm{Li}_{1.3} \mathrm{Al}_{0.3} \mathrm{Ti}_{1.7}\left(\mathrm{PO}_{4}\right)_{3}$ and electrode materials $\left(\mathrm{TiO}_{2}\right.$ and $\left.\mathrm{FePO}_{4}\right)$ were prepared to investigate interfacial structure and ionic conductivity at the interface between the solid electrolyte and electrode materials. It was revealed that lithium ions in the solid electrolyte were attracted to the cathode materials with increasing electrode potential, which increases lithium vacancies in the solid electrolyte. For the $\mathrm{FePO}_{4}$ containing composites, due to the high electrode potential, lithium transfer across the interface and ionic conduction through the cathode materials was remarkable. The results suggest that severe lithium depletion occurs and interfacial resistance is large at the interface of high ionic conductors and cathode materials. The space charge layer thickness is also discussed.
\end{abstract}

Keywords: lithium ion battery; solid electrolyte; interface; space charge layer 


\section{Introduction}

New energy storage systems with high energy density and high power density are strongly required to solve energy problems, i.e. efficient energy consumption and effective usage of renewable energies. Lithium ion batteries (LIBs) and related batteries are supposed to be one of promising energy storage devices [1-6]. LIBs used for those purpose would be much larger than conventional LIBs, and all solid state batteries that employ solid electrolytes (especially inorganic ceramics electrolytes) attract interests because of their advantages that are hardly achieved by conventional batteries with liquid organic electrolytes [7-9]. With solid electrolytes, reliability and safety of batteries are improved because they are nonflammable, which are very important for large-scale battery systems. With dense ceramic solid electrolytes, metallic lithium is supposed to be applied as a negative electrode, which forms dendritic lithium deposition on a charge process and causes short circuits for liquid electrolytes [10]. If metallic lithium is available, the capacity of battery will be drastically increased.

The drawback of the all solid state batteries is their poor power density. This problem can be traced back to their relatively poor ionic conductivity and interfacial resistance between electrodes and solid electrolytes. On the ionic conductivity, new ionic conductors with high conductivity have been developed [11-17]. $\mathrm{Li}_{10} \mathrm{GeP}_{2} \mathrm{~S}_{12}$, which was first developed by Kanno, shows the highest conductivity of $10^{-2} \mathrm{~S} \mathrm{~cm}^{-1}$ at room temperature [17]. Assuming that the transference number of $\mathrm{Li}^{+}$in this solid electrolyte is unity, this material is comparable to or even surpasses liquid organic electrolytes on lithium ion conductivity. On the interfacial resistance, even the mechanism is still unclear, although there have been several reports on the interfacial phenomena: space charge layer effect [18, 19], formation of interfacial phases [20-22], and lattice mismatch at the 
interface between a solid electrolyte and cathode [22]. Interfacial phenomena are also investigated from a theoretical viewpoint [23]. But a precise model is required to reproduce the actual system. Recently, several studies have been reported on interfaces between solid electrolytes and cathodes that cannot be explained by prevailing theories and phenomena. Yamamoto et al. observed potential profiles across a battery consisting of $\mathrm{LiCoO}_{2}$ and $\mathrm{Li}_{1-x-y} \mathrm{Al}_{y} \mathrm{Ti}_{2-y} \mathrm{Si}_{x} \mathrm{P}_{3-x} \mathrm{O}_{12}$ as a cathode and a solid electrolyte, respectively [24]. They found that the potential gradually decreased in the solid electrolyte for about 1 $\mu \mathrm{m}$ in thickness, which is much thicker than typical thickness of the space charge layer (less than $10 \mathrm{~nm}$ ). Unclarity of the interfacial phenomena arises from difficulty of analysis of thin layers sandwiched between two solid-state materials. Only a few techniques using transmission electron microscopy or X-ray absorption spectroscopy are applied to the solid-solid interface study, but obtained information is still limited.

We have investigated local structure of interfaces using nanocomposites of solid electrolytes and active materials. In the nanocomposites, interfaces dominantly affect the properties of the composites, and the interfacial phenomena can be easily detected with normal techniques $[25,26]$. In a previous work, we studied the effect of active materials on solid electrolytes, and revealed that lithium vacancy increases at the interface of $\mathrm{Li}_{2} \mathrm{SiO}_{3}$ (LSO) adjacent to high potential cathode materials [27]. LSO shows poor ionic conductivity and is less attractive as a solid electrolyte for all solid state batteries. On the other hand, $\mathrm{Li}_{1.3} \mathrm{Al}_{0.3} \mathrm{Ti}_{1.7}\left(\mathrm{PO}_{4}\right)_{3}$ (LATP) shows rather high conductivity of $10^{-3} \sim 10^{-4} \mathrm{~S}$ $\mathrm{cm}^{-1}$ at room temperature [11]. The difference of these two electrolytes is their major charge carrier: lithium vacancy $\left(V_{\mathrm{Li}}{ }^{\prime}\right)$ and lithium ion $\left(\mathrm{Li}_{\mathrm{Li}}\right)$ in LSO and LATP, respectively. In this paper, we report the cathode effects at the interface of LATP. As active materials, two materials with different electrode potentials were employed: anatase 
$\mathrm{TiO}_{2}$ (TO; open circuit potential (OCP) $\sim 3.3 \mathrm{~V}$ vs. $\mathrm{Li}^{-\mathrm{Li}^{+}}$) and $\mathrm{FePO}_{4}$ (FPO; OCP $\sim 3.5 \mathrm{~V}$ vs. $\left.\mathrm{Li} / \mathrm{Li}^{+}\right)$.

\section{Experimental}

Nano LATP was prepared from LATP powder, which was synthesized by solid state reaction using $\mathrm{Li}_{2} \mathrm{CO}_{3}, \mathrm{Al}_{2} \mathrm{O}_{3}, \mathrm{TiO}_{2}$, and $\left(\mathrm{NH}_{4}\right)_{2} \mathrm{HPO}_{4}$. These four chemicals were obtained from Kishida Chemical Co. Ltd. with a purity of 99\%. First, the mixture of starting materials was heated at $900^{\circ} \mathrm{C}$ for 2 hours in air. Then, the product was milled and heated again with the same condition. Finally, nano LATP was obtained by milling at $650 \mathrm{rpm}$ for $160 \mathrm{~min}$ in acetone with a $\mathrm{ZrO}_{2}$ pot and $\mathrm{ZrO}_{2}$ beads ( $0.2 \mathrm{~mm}$ in a diameter). Nano $\mathrm{TiO}_{2}$ (anatase-type) was supplied as a reference catalyst JRC-TiO-1 by Catalysis Society of Japan. Nano $\mathrm{FePO}_{4}$ was synthesized by a method described previously [27]. These nanoparticles of active materials were preheated in $\mathrm{N}_{2}$ at $200^{\circ} \mathrm{C}$ to remove adsorbed water, and then the nanocomposites were prepared by mechanical milling of the mixture of nanosized solid electrolyte (LATP) and nanosized active materials (TO and FPO) at $150 \mathrm{rpm}$ for 2 hours in dry Ar. The volume fraction of nanosized active materials in the composites was $40 \%$. All the synthesis procedure was carried out in a dry $\mathrm{N}_{2}$ or $\mathrm{Ar}$ atmosphere to avoid adsorption of water that may cause side reactions. The particle sizes and dispersion of the nanoparticles and nanocomposites were analyzed by field-emission scanning electron microscopy (FE-SEM) equipped with energy dispersive X-ray (EDX) spectrometer (JSM-7500FAM; JEOL Ltd., Japan) and $\mathrm{N}_{2}$ sorption at $77 \mathrm{~K}$ (BELSORP-mini II, BEL Japan Inc., Japan). The crystal structure was investigated by X-ray diffraction (XRD) on a RINT-2200 (Rigaku Corporation, Japan).

The electric conductivity of the nanoparticles and the nanocomposites were obtained by a.c. impedance spectra with a frequency range from $1 \mathrm{MHz}$ to $0.1 \mathrm{~Hz}$ with an 
oscillation voltage of $0.1 \mathrm{~V}$, which were conducted on a frequency response analyzer S1260 (Solartron analytical, U.K.). Specimens were uni-axially pressed into disks (7 mm in diameter and $0.5 \sim 0.7 \mathrm{~mm}$ in thickness) at $10 \mathrm{MPa}$. Gold electrodes were attached on both sides by sputtering. LSO, of which lithium ionic transference number is unity, showed a divergent straight line on Nyquist plots at a low frequency region. On the other hand, for the composites containing FPO, Nyquist plots converged on a point on the real axis, suggesting electronic conduction. To estimate the ionic conductivity, pure electronic conductivity was obtained by d.c. polarization curves with a d.c. bias of $0-2.0 \mathrm{~V}$, which were recorded on a potentio-/galvanostat S1287 (Solartron analytical, U.K.). All the conductivity measurements were carried out in an $\mathrm{Ar}$ atmosphere from $350^{\circ} \mathrm{C}$ to a room temperature.

\section{Results and Discussions}

In XRD profiles of synthesized LATP, a trace of $\mathrm{AlPO}_{4}$ was confirmed, but other peaks demonstrated the formation of the NASICON-type LATP was successfully obtained. No contaminant such as $\mathrm{ZrO}_{2}$ was not observed, after the ball-milling of bulk LATP. Nano LATP was c.a. $200 \mathrm{~nm}$ in a diameter that was observed by FE-SEM.

Figure 1 shows XRD patterns of nano LATP, LATP-TO and LATP-FPO. For LATP-TO, the impurity phase of $\mathrm{AlPO}_{4}$ seemed to be slightly increased, but no significant peak shift was confirmed on addition of TO. On the other hand, for LATP-FPO, FPO caused peak shift towards lower diffraction angle of LATP, meaning expansion of lattice. Such peak shift is also confirmed in LSO systems [27]. LSO-TO exhibited no peak shift while LSO-FPO did. The lattice expansion of LATP indicates lithium transfer from LATP to the FPO across interfaces. 
The ionic conductivity of these materials is shown in Fig. 2. The conductivity of nano LATP in Figs. 2(a) and 2(b) are different. This is because nano LATP used for LATP-TO and LATP-FPO were prepared on different occasions and exhibit different particle sizes of nano LATP and amounts of impurity. Therefore, it does not make any sense to compare two nano LATPs with each other, the nano LATP and nano composites can be compared. The ionic conductivity of both composites was lower than the pristine nano LATP, which is the opposite phenomena to LSO-TO and LSO-FPO, where TO and FPO caused increase in the ionic conductivity [27]. For LSO systems, the experimental results were explained with the space charge layer effects [28]. Lithium ions in LSO are attracted towards active materials, depending on electrode potential (i.e., energy gain on $\mathrm{Li}^{+}$insertion). With increasing electrode potential, more lithium ions are attracted and lithium vacancy increases in the space charge layer of the solid electrolytes. Lithium vacancy is the major carrier in LSO and ionic conductivity increases. On the other hand, in LATP, major carrier is lithium ions with partial site occupancy, which can be regarded as interstitial lithium ions. When a high-potential electrode attracts lithium ions from solid electrolytes, lithium ions are depleted at the interface and ionic conductivity decreases (Fig. 3). The interfacial depletion layer is a critical problem for ionic conduction of LATP because when LATP particles are covered with depletion layer, it loses ionic conductivity. Even though the composites contains 60 vol.\% of LATP, volume fraction of highly conducting region would be much lower and the conductivity of the composites is more depressed than expected by the percolation theory, which is schematically shown in Fig. 3(a). In addition, although there are mobile lithium ions inside particles of LATP, they have to cross highly resistive layer to reach neighboring particles. Note that the change for LATP-FPO is comparable to that for LATP-TO, although electrode potential of FPO $\left(\sim 3.5 \mathrm{~V}\right.$ vs. $\left.\mathrm{Li} / \mathrm{Li}^{+}\right)$is higher than TO $(\sim 3.3 \mathrm{~V}$ vs. 
$\left.\mathrm{Li} / \mathrm{Li}^{+}\right)$. This is explained by the lithium conduction via FPO interface as suggested previously [27]. At the interface, a lot of lithium ions are attracted toward high-potential FPO. The attractive force is so strong that lithium ions are inserted into FPO to some extent and form Li-inserted layer at the interface of FPO [29]. Therefore, lithium ions can migrate through the interfacial layer on the FPO side. The conduction pathway through FPO is also supported by the activation energy of ionic conduction (see Fig. 2). For LATP-TO $(0.72 \mathrm{eV})$, the activation energy is larger than pristine LATP $(0.54 \mathrm{eV})$. This is accounted for by the increased contribution of the grain-boundry (interfacial) resistance due to the depletion layer. On the other hand, LATP-FPO $(0.59 \mathrm{eV})$ showed almost the same activation energy as LATP $(0.55 \mathrm{eV})$. This is reasonably explained by the activation energy for ionic conduction in $\mathrm{LiFePO}_{4}, 0.55-0.59 \mathrm{eV}$ [30].

Here we focus on the thickness of the space charge layer. XRD profiles of LSO-FPO and LATP-FPO demonstrated lattice expansion of solid electrolytes, meaning that interfacial region affected by FPO is at least thicker than radius of LATP ( $50 \mathrm{~nm})$. This value is much thicker than calculated value (0.2 nm for Mott-Schottky type [31]) by the space charge layer model. This phenomenon may be similar to the interfacial potential profile [24]. In order to explain the discrepancy of the space charge layer thickness, defects pair (defects association) should be taken into consideration. For LATP, defects are formed as follows:

$$
\mathrm{LiAl}\left(\mathrm{PO}_{4}\right)_{4 / 3} \stackrel{\mathrm{LiTi}_{2}\left(\mathrm{PO}_{4}\right)_{3}}{\longrightarrow} \mathrm{Li}_{\mathrm{i}}{ }^{\bullet}+\mathrm{Al}_{\mathrm{Ti}}{ }^{\prime}+4 / 3\left(\mathrm{PO}_{4}\right)_{\mathrm{PO} 4}
$$

Positive defect $\mathrm{Li}_{\mathrm{i}}{ }^{\prime}$ and negative defect $\mathrm{Al}_{\mathrm{Ti}}$ ' attract each other and form defect pairs:

$$
\mathrm{Li}_{\mathrm{i}}{ }^{\bullet}+\mathrm{Al}_{\mathrm{Ti}^{\prime}}{ }^{\prime} \leftrightarrow\left(\mathrm{Li}_{\mathrm{i}}{ }^{\cdot}-\mathrm{Al}_{\mathrm{Ti}}{ }^{\prime}\right)^{\mathrm{x}}
$$

The exact value of the equilibrium constant of defects-association in LATP is unknown, but may be estimated from other values. Association enthalpy $\left(\Delta H_{\text {ass }}\right)$ of defects in 
Cd-doped $\mathrm{AgCl}\left(\mathrm{Cd}_{\mathrm{Ag}} \cdot\right.$ and $\left.V_{\mathrm{Ag}^{\prime}}\right)$ is reported to be $-0.3 \sim-0.5 \mathrm{eV}$ [32]. For LSO, formation enthalpy of Frenkel-defects is obtained to be $1.2 \mathrm{eV}$ from the activation energy of intrinsic region of temperature dependent ionic conductivity [27]. Using $\Delta H_{\text {ass, }}$ density of mobile charge carrier ( $N_{\infty}$, mobile) is obtained from

$$
N_{\infty, \text { mobile }}=N_{\infty} \exp \left(\frac{\Delta H_{\text {ass }}}{R T}\right)
$$

From $N_{\infty}$, mobile, the space charge layer thickness (MS) is $27 \mathrm{~nm}$ and $27 \mu \mathrm{m}$ for $\Delta H_{\text {ass }}$ of $-0.5 \mathrm{eV}$ and $-1.2 \mathrm{eV}$, respectively, which agree with experimental results.

\section{Conclusion}

At interfaces of solid electrolytes and active materials, lithium-ion transfer across the interfaces occurs, which depends on potential of the active materials. The $\mathrm{Li}^{+}$transfer causes change in the ionic conductivity at the interface and, in some cases, changes in the lattice expansion.

\section{Acknowledgements}

This work was financially supported by Tokuyama Science Foundation.

\section{References}

[1] P. G. Bruce, Chem. Comm., 19 (1997) 1817-1824.

[2] C. Fellner, J. Newman, J. Power Sources, 85 (2000) 229-236.

[3] I. Moriguchi, R. Hidaka, H. Yamada, T. Kudo, H. Murakami, N. Nakashima, Adv. Mater. , 18 (2006) 69-73.

[4] H. Yamada, K. Tagawa, M. Komatsu, I. Moriguchi, T. Kudo, J. Phys. Chem. C, 111 (2007) 8397-8402. 
[5] P. G. Bruce, B Scrosati, J.-M. Tarascon, Angew. Chem. Int. Ed., 47 (2008) 2930-2946.

[6] H. Yamada, Y. Watanabe, I. Moriguchi, T. Kudo, Solid State Ionics, 179 (2008) 1706-1709.

[7] K. M. Abraham, Electrochim. Acta, 38 (1993) 1233-1248.

[8] K. Takada, T. Inada, A. Kajiyama, M. Kouguchi, H. Sasaki, S. Kondo, Y. Michiue, S. Nakano, M. Tabuchi, M. Watanabe, Solid State Ionics, 172 (2004) 25-30.

[9] J. B. Bates, N. J. Dudney, B. Neudecker, A. Ueda, C. D. Evans, Solid State Ionics, 135 (2000) 33.

[10] D. Aurbach, A. Zaban, A. Schechter, Y. Ein-Eli, E. Zinigrad, B. Markovsky, J. Electrochem. Soc., 142 (1995) 2873-2882.

[11] H. Aono, E. Sugimoto, Y. Sadaoka, N. Imanaka, G. Adachi, Chem. Lett., 19 (1990) 331-332.

[12] Y. Inaguma, C. Liquan, M. Itoh, T. Makamura, T. Uchida, H. Ikuta, M. Wakihara, Solid State Comm., 86 (1993) 689-693.

[13] R. Kanno, M. Murayama, J. Electrochem. Soc., 148 (2001) A742-A746.

[14] M. Tatsumisago, A. Hayashi, in Solid State Ionics for Batteries, T. Minami, M. Tatsumisago, C. Iwakura, S. Kohjiya, I. Tanaka, Editor, Ch. 3.2, Springer, Tokyo, (2005).

[15] R. Murugan, V. Thangadurai, W. Weppner, Angew. Chem. Int. Ed., 46 (2007) 7778-7781.

[16] P. Knauth, Solid State Ionics, 180 (2009) 911-916. 
[17] N. Kamaya, K. Homma, Y. Yamakawa, M. Hirayama, R. Kanno, M. Yonemura, T. Kamiyama, Y. Kato, S. Hama, K. Kawamoto, A. Mitsui, Nature Mater., 10 (2011) 682-686.

[18] N. Ohta, K. Takada, L. Zhang, R. Ma, M. Osada, T. Sasaki, Adv. Mater., 18 (2006) 2226-2229.

[19] N. Ohta, K. Takada, I. Sakaguchi, L. Zhang, R. Ma, K. Fukuda, M. Osada, T. Sasaki, Electrochem. Commun., 9 (2007) 1486-1490.

[20] A. Sakuda, H. Kitaura, A. Hayashi, K. Tadanaga, M. Tatsumisago, Electrochem. Solid-State Lett., 11 (2007) A1-A3.

[21] A. Sakuda, A. Hayashi, M. Tatsumisago, Chem. Mater., 22 (2010) 949-956.

[22] T. Okumura, T. Nakatsutsumi, T. Ina, Y. Orikasa, H. Arai, T. Fukutsuka, Y. Iriyama, T. Uruga, H. Tanida, Y. Uchimoto, Z. Ogumi, J. Mater. Chem., 21 (2011) 10051-10060.

[23] M. Landstorfer, S. Funken, T. Jacob, Phys. Chem. Chem. Phys., 13 (2011) 12817-12825.

[24] K. Yamamoto, Y. Iriyama, T. Asaka, T. Hirayama, H. Fujita, C. A. J. Fisher, K. Nonaka, Y. Sugita, Z. Ogumi, Angew. Chem. Int. Ed., 49 (2010) 4414-4417.

[25] H. Yamada, I. Moriguchi, T. Kudo, Solid State Ionics, 176 (2005) 945-953.

[26] H. Yamada, A. J. Bhattacharyya, J. Maier, Adv. Funct. Mater., 16 (2006) 525-530.

[27] H. Yamada, Y. Oga, I. Saruwatari, I. Moriguchi, J. Electrochem. Soc., 159 (2012) A380-A385.

[28] J. Maier, J. Phys. Chem. Solids, 46 (1985) 309-320.

[29] M. E. Garcia, E. Webb III, S. H. Garofalini, J. Electrochem. Soc., 145 (1998) 2155-2164.

[30] R. Amin, P. Balaya, J. Maier, Electrochem. Solid-State Lett., 10, (2007) A13-A16. 
[31] X. Guo, I. Matei, J. Jamnik, J.-S. Lee, J. Maier, Phys. Rev. B, 76 (2007) 125429.

[32] J. Corish, P. W. M. Jacobs, Surf. Def. Prop. Solids, 2 (1973) 160-228. 


\section{Figure Captions}

Figure 1. XRD profiles of nano LATP (a) LATP-TO and (b) LATP-FPO. The volume fraction of active materials are 0.4 .

Figure 2. $\mathrm{Li}^{+}$conductivities and activation energies of $\mathrm{Li}^{+}$conduction of nano LATP, (a) nanocomposite of LATP-TO and (b) LATP-FPO with a volume fraction of active materials of 0.4 .

Figure 3. (a) Schematic image of LATP-FPO nanocomposite. Gray and blue parts represent FPO and LATP particles, respectively. Pale blue region in the LATP particles is the depletion region. (b), (c) Schematic vacancy and potential profiles at the interfaces of LATP-side for the composite LATP-FPO (OCP = $3.5 \mathrm{~V})$. Blue dashed bold line: potential $(\phi)$, dashed black line: chemical potential of lithium vacancy $\left(\left[V_{\mathrm{Li}}{ }^{\prime}\right]\right)$ and dashed green line: chemical potential of lithium ion $\left(\left[\mathrm{Li}_{\mathrm{Li}}\right]\right)$. Defect profiles are drawn assuming Mott-Schottkey distribution. 

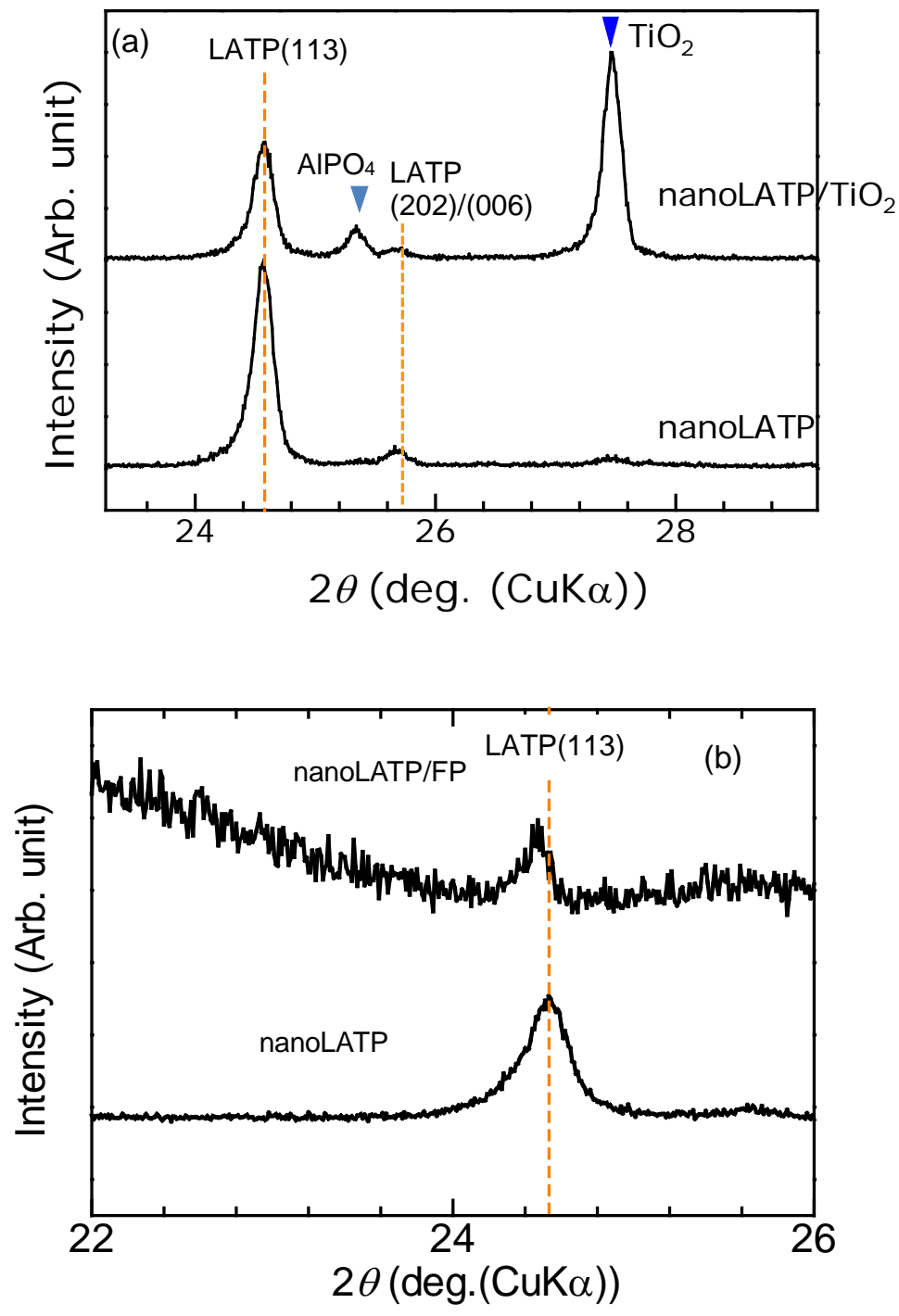

Figure 1

H. Yamada, et al. 

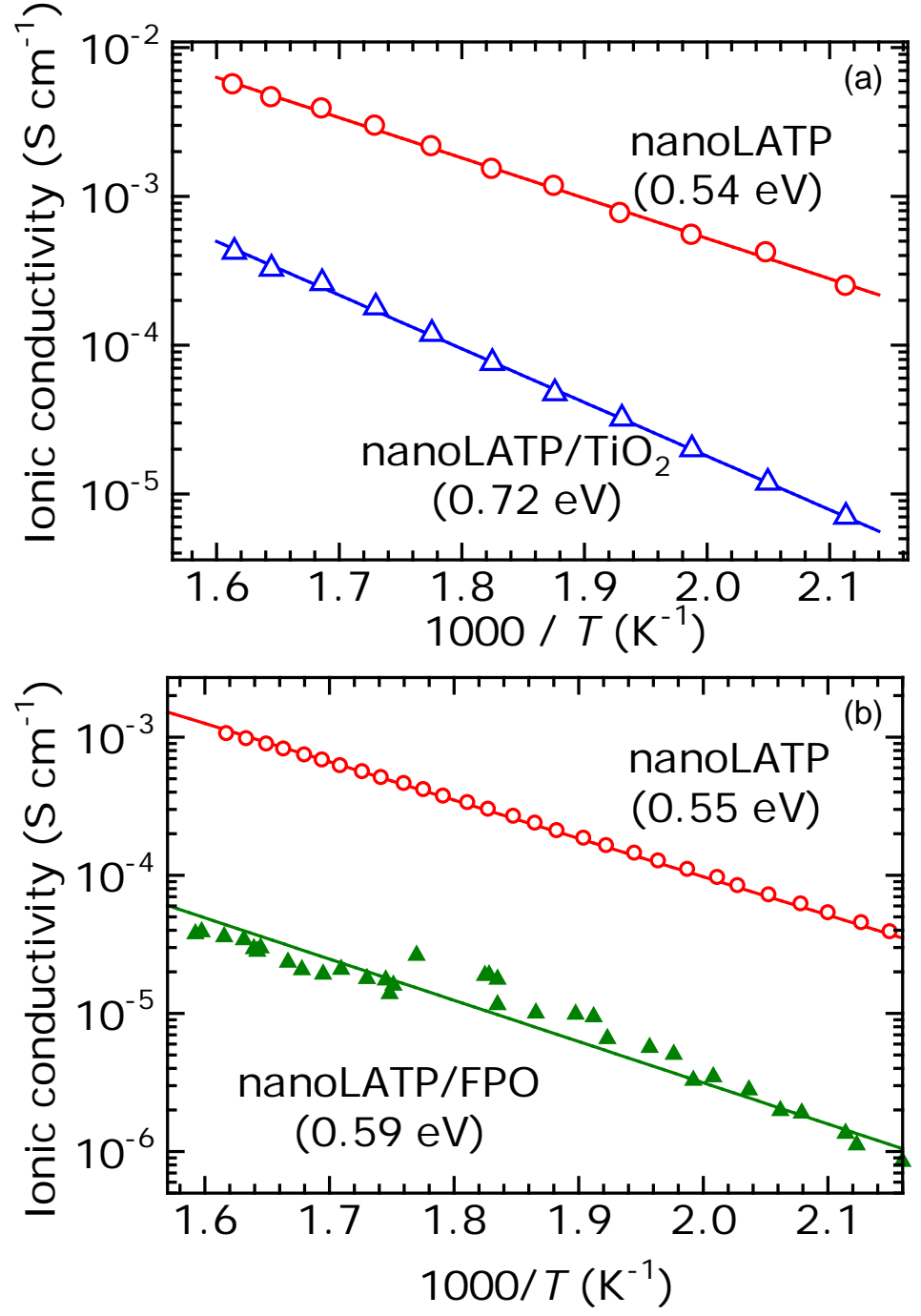

Figure 2

H. Yamada, et al. 
(a) LATP-FPO (3.5 V)

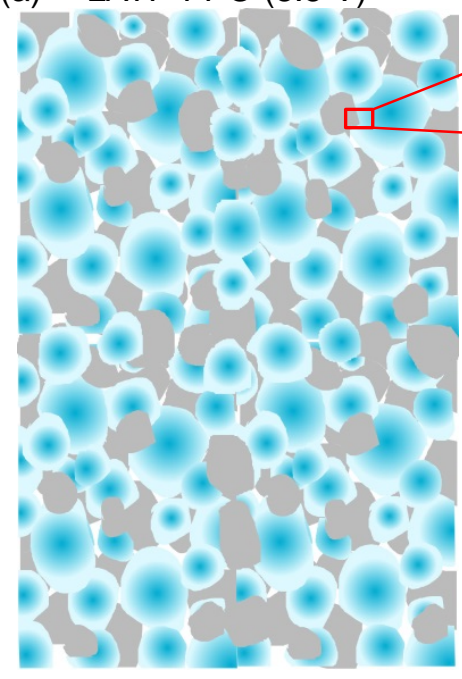

(b)
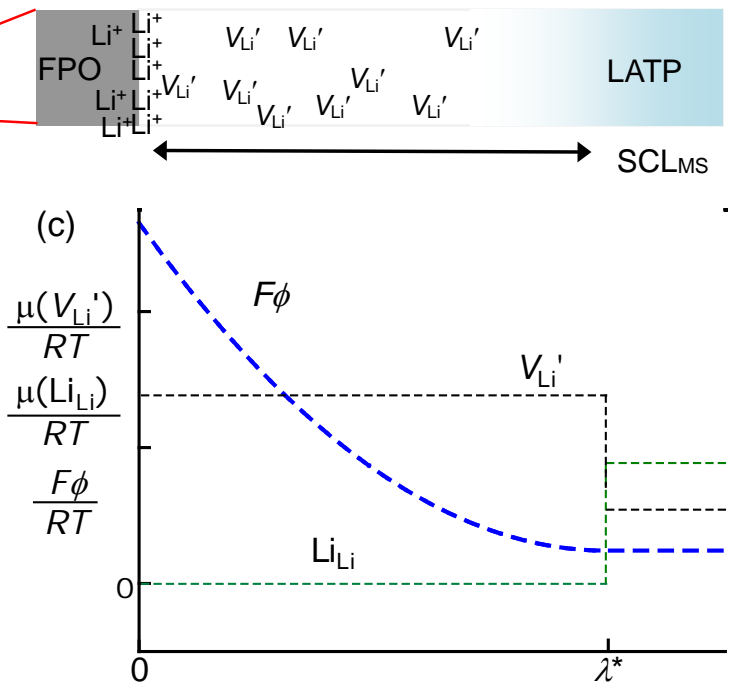

Length from the interface inside LATP

\section{Figure 3}

H. Yamada, et al. 